\title{
Field-testing liquefaction models based on geospatial vs. geotechnical data
}

\author{
Test des modèles géospatiaux et géotechniques de risque de liquéfaction sur le terrain
}

\author{
Brett W. Maurer \\ Department of Civil and Environmental Engineering, University of Washington, United States, bwmaurer@uw.edu
}

\begin{abstract}
This study assesses the relative efficacy of liquefaction models based on geospatial vs. geotechnical data. In particular, state-of-practice geotechnical models based on the Cone Penetration Test (CPT) are compared to geospatial models that use readily available no-cost data. This assessment is performed using a database of 9,623 liquefaction case studies compiled from the 2010-2016 Canterbury, New Zealand, Earthquakes. While the top-performing model is CPT-based, the geospatial models perform surprisingly well given their simplicity. In particular, a region-specific geospatial model out-performs some CPT-based methods. While further research is needed, the presented findings are provocative considering the relative cost and complexity of the geotechnical models. Accordingly, performance assessments of geospatial vs. geotechnical models are ongoing for more than 20 additional earthquakes.
\end{abstract}

\section{INTRODUCTION}

Semi-empirical models based on in-situ test data have become the standard of practice worldwide for predicting soil liquefaction. Since the inception of the Standard Penetration Test (SPT) based "simplified-procedure" in 1971, variants based on other in-situ measurements have been developed, including Cone Penetration Test (CPT) indices and shear wave velocity (Vs), among others. More recently, models based soley on geospatial data were proposed (Zhu et al., 2014a; 2014b). Similar to the US Geological Survey's PAGER system, which provides automated content concerning earthquake impacts, these models aim to predict liquefaction for rapid response and loss estimation using readily available geospatial and seismic data (e.g. digital elevation models, DEMs; and peak ground accelerations, PGAs). However, the predictive capabilities of geospatial and geotechnical models have not been directly compared, which could elucidate techniques for improving each approach, and which would provide a baseline for measuring improvements. Accordingly, the focus of this study is an assessment of the realtive efficacy of geospatial versus geotechnical liquefaction models using a database of 9,623 case-studies compiled from the 2010-2016 Canterbury, New Zealand, Earthquake Sequence (CES), which induced widespread liquefaction in the city of Christchurch (e.g., Maurer, 2016). Towards this end, the models will be assessed on their ability to predict whether sites had manifestations of liquefaction at the ground surface.

\section{GEOTECHNICAL \& GEOSPATIAL MODELS}

Two geotechnical models and two geospatial models will be assessed and compared. The geotechnical models are Idriss and Boulanger (2008) and Boulanger and Idriss (2014), henceforth referred to as IB08 and BI14, respectively. However, IB08 and BI14 do not directly quantify the likelihood of liquefaction manifestations at the ground surface, but rather, compute the safety factor against liquefaction triggering $\left(F S_{l i q}\right)$ at depth. Therefore, to link $F S_{l i q}$ at depth to manifestations at the ground surface, liquefaction damage measures $(L D M s)$ are commonly used in practice. In brief, $L D M s$ take into account the thickness and depth of strata predicted to liquefy, among other factors, and integrate over the soil profile to predict its cumulative response. This study thus investigates the IB08 and BI14 models used in conjunction with the following LDMs: (1) the liquefaction potential index (LPI) (Iwasaki et al. (1978); (2) a modified LPI, termed LPIISH (Maurer et al., 2015a); (3) predicted postliquefaction 1D settlement (IDS) (Zhang et al., 2002); and (4) the liquefaction severity number ( $L S N)$ (Van Ballegooy et al., 2014).

The two geospatial models to be assessed herein were developed by Zhu et al. (2014a) and have the general form:

$$
\mathrm{P}(X)=\left(1+\mathrm{e}^{-X}\right)^{-1}
$$

where $X$ is a set of geospatial variables, and $P(X)$ is the probability of liquefaction manifestation. The first model was developed for use worldwide and is referred to as the "Global Geospatial Model," wherein $X$ is defined as (Zhu et al., 2014a):

$$
\begin{aligned}
X= & 24.10+2.067 \cdot \ln \left(P G A_{M}\right)+0.355 \cdot C T I \\
& -0.4784 \cdot \ln \left(V_{s 30}\right)
\end{aligned}
$$

where $P G A_{M}$ is the magnitude-weighted $P G A$ computed using a magnitude scaling factor; $C T I$ is the compound topographic index (Moore et al., 1991), and $V_{s 30}$ is the average shear-wave velocity for the upper 30-m depth and is estimated from topographic slope. The second model was developed specifically for Christchurch and is referred to herein as the "Regional Geospatial Model," for which $X$ is defined as (Zhu et al., 2014a):

$$
\begin{aligned}
X= & 25.45+2.476 \cdot \ln \left(P G A_{M}\right)-0.323 \cdot d_{r 3} \\
& -4.241 \cdot \ln \left(V_{s 30}\right)
\end{aligned}
$$

where $d_{r 3}$ is the distance to a stream of order three or greater, as classified by the Strahler stream-ordering method.

\section{DATA \& METHODOLOGY}

This study uses data from the $\mathrm{M}_{\mathrm{w}} 7.1$, Sept 2010 Darfield earthquake, the $M_{w} 6.2$, Feb 2011 Christchurch earthquake, and the $\mathrm{M}_{\mathrm{w}} 5.7$, Feb 2016 Christchurch earthquake, from which a combined 9,623 liquefaction case studies were compiled. These consist of PGAs, liquefaction observations, extensive geotechnical data, and readily available geospatial information.

\subsection{Data Shared by Geotechnical and Geospatial Models}

Observations of liquefaction were compiled and classified using the Green et al. (2014) criteria. Of the 9,623 cases, 58\% are "No Manifestation" cases and $42 \%$ are "Manifestation" cases. PGAs were computed with the Bradley (2013) procedure, which has been used by many CES studies (e.g., Maurer et al., 2015b). This procedure statistically coalesces estimates from ground-motion prediction equations with strong-motion recordings.

\subsection{Geotechnical Data \& Methodology}

CPT soundings were performed at each case-history site. For further coverage of CPT data, see Maurer et al. (2015c). Ground water table (GWT) depths were sourced from regional models that capture spatiotemporal fluctuations. Prior to using IB08 and BI14, liquefaction-susceptible soils were inferred from the CPT soil-behavior-type index $\left(I_{c}\right)$, such that soils with $I_{c}<2.50$ were assumed susceptible. IB08 and BI14 then compute $F S_{\text {liq }}$ as a function of fines-content $(F C)$. Accordingly, $F C$ was estimated by a regional $I_{c}-F C$ correlation (Maurer, 2016). LPI, LPIISH, $I D S$, and $L S N$ values were then computed using IB08 and BI14. 


\subsection{Geospatial Data and Methodology}

Geospatial variables $C T I, d_{r 3}$, and $V_{s 30}$ were derived from a 90-m resolution Shuttle Radar Topography Mission (SRTM) DEM of New Zealand (Jarvis et al., 2008). These variables were developed using the methods adopted by Zhu et al. (2014a), to which the reader is referred for additional information. $\mathrm{P}(X)$ was then computed for each of the 9,623 liquefaction case studies using Geospatial Models 1 and 2, as defined in Equations 1-3.

\subsection{Receiver Operating Characteristic (ROC) Analyses}

Model efficacy is assessed using receiver operating characteristic (ROC) analysis, which plots the True Positive Rate (i.e., liquefaction is observed as predicted) vs. the False Positive Rate (i.e., liquefaction is predicted, but not observed) as a function of index-test results (e.g., $L P I$ or $\mathrm{P}(X)$ ). While no single parameter fully characterizes performance, the area under a ROC curve $(A U C)$ is used herein and is the probability that "Manifestation" cases have higher index-values than "No Manifestation" cases. A larger $A U C$ thus indicates better model performance.

\section{RESULTS \& DISCUSSION}

To demonstrate the use of ROC analyses, ROC curves are plotted in Figure 1 for the Global and Regional Geospatial Models, and for the IB08 and BI14 models used in conjunction with LPI. Of these four models, BI14 (LPI) and the Global Geospatial Model are respectively the most and least efficacious, with respective $A U C$ values of 0.853 and 0.775 . However, considering the simplicity of the Geospatial Models, their performance is surprisingly good. In particular, the Regional Geospatial Model, with $A U C=0.828$, is nearly as efficacious as IB08 $(L P I)$, with $A U C=0.845$. In Figure 2 the performance of all assessed models is summarized in terms of $A U C$. It can be seen that while BI14 $\left(L P I_{I S H}\right)$ is the most efficacious, the Regional Geospatial Model outperforms some of the models based on geotechnical data. It should be noted, however, that the Regional Geospatial Model was developed specifically for Christchurch using data from the CES (the Global Geospatial Model is also partially based on CES data). Therefore, these models should also be tested using data from other earthquakes (see Zhu et al., 2014b). Nonetheless, the findings presented in Figure 2 are provocative considering the relative complexity of the CPT-based models and the costs of their requisite inputs. Accordingly, performance assessments of geospatial vs. geotechnical models are ongoing for more than 20 additional earthquakes.

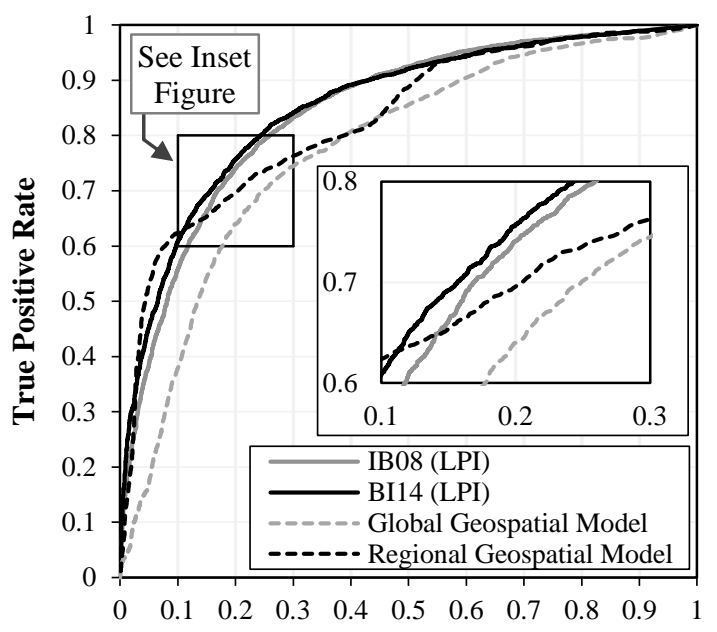

False Positive Rate

Figure 1. Receiver operating characteristic analyses of liquefaction prediction models based on geotechnical versus geospatial data.

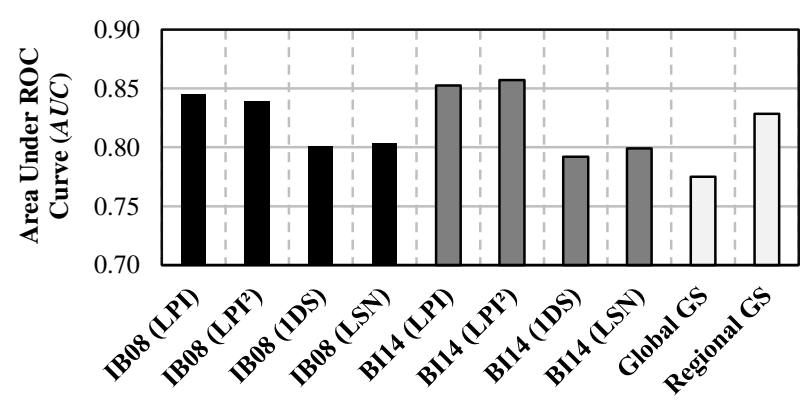

Figure 2. Summary of model performance, as quantified by the area under a ROC curve $(A U C) ; \mathrm{LPI}^{2}=L P I_{I S H} ; \mathrm{GS}=$ Geospatial Model.

\section{CONCLUSION}

This study analyzed 9,623 liquefaction case studies from the 2010-2016 CES to assess the relative efficacy of geospatial vs. geotechnical liquefaction models. Considering their simplicity, the geospatial models performed exceedingly well (e.g., the Regional Geospatial Model outperformed some geotechnical models). These analyses are preliminary and will be expanded using additional case studies from earthquakes worldwide.

\section{REFERENCES}

Bradley, B.A. 2013. Site-specific and spatially-distributed ground motion intensity estimation in the 2010-2011 Christchurch earthquakes. Soil Dynamics and Earthquake Engineering, 48, 35-47.

Boulanger, R.W. and Idriss, I.M. 2014. CPT and SPT based liquefaction triggering procedures. Report No. UCD/CGM.-14/01, Center for Geotech. Modelling, Civil \& Environmental Eng., UC Davis, CA.

Green, R.A., Cubrinovski, M., Cox, B., Wood, C., Wotherspoon, L., Bradley, B., \& Maurer, B.W. 2014. Select Liquefaction Case Histories from the 2010-2011 Canterbury Earthquake Sequence. Earthquake Spectra, 30(1), 131-153.

Idriss, I.M. \& Boulanger, R.W. 2008. Soil liquefaction during earthquakes. Monograph MNO-12, EERI, Oakland, CA, 261 pp.

Iwasaki, T., Tatsuoka, F., Tokida, K., \& Yasuda, S. 1978. A practical method for assessing soil liquefaction potential based on case studies at various sites in Japan. 2nd International Conference on Microzonation, Nov 26-Dec 1, San Francisco, CA, USA

Jarvis, A., Reuter, H.I. Nelson, A., Guevara, E. 2008. Hole-filled SRTM for the globe. Version 4, (http://srtm.csi.cgiar.org).

Maurer, B.W., Green, R.A., and Taylor, O.S. 2015a. Moving towards an improved index for assessing liquefaction hazard: lessons from historical data. Soils and Foundations 55(4), 778-787.

Maurer, B.W., Green, R.A., Cubrinovski, M., and Bradley, B. 2015b. Assessment of CPT-based methods for liquefaction evaluation in a liquefaction potential index framework. Géotechnique 65(5), 328-336.

Maurer, B.W., Green, R.A., Cubrinovski, M., Bradley, B. 2015c. Finescontent effects on liquefaction hazard evaluation for infrastructure during the 2010-2011 Canterbury, New Zealand earthquake sequence. Soil Dynamics and Earthquake Engineering, 76, 58-68.

Maurer, B.W. 2016. Moving towards an improved liquefaction hazard framework: lessons resulting from the 2010-2011 Canterbury, New Zealand, earthquake sequence. $\mathrm{PhD}$ Dissertation, Virginia Tech.

Moore, I.D., Grayson, R.B., Ladson, A.R. 1991. Digital terrain modeling: A review of hydrological, geomorphological and biological applications. Hydrological Processes 5, 3-30.

Van Ballegooy, S., Malan, P., Lacrosse, V., Jacka, M.E., Cubrinovski, M., Bray, J.D., O'Rourke, T.D., Crawford, S.A., and Cowan, H. 2014. Assessment of liquefaction-induced land damage for residential Christchurch. Earthquake Spectra, 30(1): 31-55.

Zhang, G., Robertson, P.K., Brachman, R.W.I. 2002. Estimating liquefaction-induced ground settlements from CPT for level gorund. Canadian Geotechnical Journal, 39(5), 1168-1180.

Zhu, J., Daley, D., Baise, L.G., Thompson, E.M., Wald, D.J., and Knudsen, K.L. 2014a. A geospatial liquefaction model for rapid response and loss estimation. Earthquake Spectra 31(3), 1813-1837.

Zhu, J. Baise, L.B., Thompson, E.M., Wald, D.J., and Magistrale, H. 2014b. Testing national and regional geospatial liquefaction models in the United States. $10^{\text {th }}$ US National Conference on Earthquake Engineering, July 20-26, Anchorage, AK, USA. 